\title{
DESEMPENHO DE COELHOS EM CRESCIMENTO ALIMENTADOS COM DIFERENTES NÍVEIS DE FENO DA RAMA DA MANDIOCA (Manihot esculenta, CRANTZ)
}

\author{
PERFORMANCE OF GROWING RABBITS FEEDING WITH DIFFERENT \\ LEVELS OF CASSAVA FOLIAGE HAY (Manihot esculenta, CRANTZ)
}

\section{Claudio Scapinello ${ }^{1}$ José Egmar Falco $^{2}$ Antonio Claudio Furlan ${ }^{1}$ Haroldo Garcia de Faria ${ }^{3}$}

\section{RESUMO}

Com o objetivo de estudar o feno do terço superior da rama da mandioca no desempenho de coelhos em crescimento, foram utilizados 32 coelhos da Raça Nova Zelândia Branco, de 50 a 70 dias de idade. Os animais foram distribuídos num delineamento experimental, em blocos casualizados dentro de sexo, com 4 tratamentos ( 4 níveis de inclusão de feno de mandioca 0 , 10,20 e 30\%) e 8 animais em cada bloco, com duas repetições dentro de cada bloco, sendo as repetições de um animal por unidade experimental. O peso vivo aos 70 dias de idade diminuiu linearmente $(P<0,05)$ à medida que se aumentou o nível de inclusão do feno da rama da mandioca nas dietas. Por outro lado, as demais características de desempenho e carcaça não foram afetadas com os níveis de inclusão do feno. Os dados indicam que o feno da rama da mandioca é viável até o nível de $20 \%$ nas rações.

Palavras-Chave: coelhos, desempenho, feno de mandioca.

\section{SUMMARY}

With the aim of studyng the hay made from the upper third of cassava foliage in development of growing rabbits, 32 rabbits, 16 males and 16 females, breed White New Zealand from 50 to 70 days of age were used. The rabbits were distributed in block randomized design within sex, with 4 treatments (4 levels of inclusion the cassava foliage hay 0,10,20 and 30\%) with eight animals in each block and 2 replicates in each block, being each replicate constituted of one animal per experimental unit. The weight at 70 days of age decresead linearly $(P<0.05)$ when the level of cassava foliage hay was increasead in diets. The other characteristics of performance and carcass were not affected with the cassava foliage hay inclusion levels. The results have showed that the levels of cassava foliage hay is viable not more than $20 \%$ of inclusion in diet
Keywords: cassava hay, performance, rabbits.

\section{INTRODUÇÃO}

A criação de coelhos é caracterizada pelo rápido crescimento, precocidade reprodutiva, alta fertilidade e curto período de gestação, fatores esses que contribuem significativamente para o aumento na produção de carne. O coelho, além de não competir com o homem pelos alimentos disponíveis, pode utilizar uma dieta à base de produtos e subprodutos com alto teor de fibra (ZINSLY et al., 1985).

O fato de o coelho possuir aparelho digestivo desenvolvido, principalmente o ceco, com ativa ação microbiana, resulta em uma alta capacidade de aproveitamento quando comparado a suínos e aves (FERREIRA et al.,1997). Trabalhos voltados ao estudo da utilização de forrageiras tropicais na formulação de dietas para coelhos são relativamente recentes ( HARRIS $\boldsymbol{e t}$ al., 1981; RAHARJJO $\boldsymbol{e} \boldsymbol{t}$ al., 1986). No Brasil, estudos como os de MENEZES FILHO (1984) e NASCIMENTO et al. (1990), entre outros, demonstram a tendência de direcionamento das pesquisas em nutrição e alimentação de coelhos para essa área ainda pouco estudada. Neste sentido, a parte aérea da mandioca, devido ao seu valor nutritivo e ao seu volume de produção, constitui um excelente potencial de arraçoamento animal.

\footnotetext{
${ }^{1}$ Departamento de Zootecnia, Universidade Estadual de Maringá, Av. Colombo 5790, 87020-900, Maringá, PR. Autor para correspondência.

${ }^{2}$ Departamento de Zootecnia, Universidade Federal de Lavras, MG.

${ }^{3}$ Biotério Central, Universidade Estadual de Maringá. 
A produção brasileira de mandioca em raiz para a safra de 1997 foi estimada em 25 milhões de toneladas (GROXKO, 1997). Segundo BARBOSA (1972) e CORRÊA (1972), aos 18 meses, a produção de ramas e folhas representa um volume semelhante à produção de raízes. Contudo, apesar da alta produção, ainda se faz pouco uso das ramas e folhas de mandioca, ocorrendo, consequientemente, considerável perda das mesmas. Diante do exposto, o objetivo do presente trabalho foi o de avaliar o desempenho de coelhos em crescimento, alimentados com rações contendo diferentes níveis de feno do terço superior da rama da mandioca.

\section{MATERIAL E MÉTODOS}

O experimento foi conduzido no Setor de Cunicultura do Departamento de Zootecnia da Universidade Federal de Lavras. Foram utilizados 32 coelhos da Raça Nova Zelândia Branco, 16 machos e 16 fêmeas, com 50 dias de idade, alojados em gaiolas de arame galvanizado, providas de comedouro semi-automático e bebedouros automáticos. As temperaturas máxima e mínima, durante o período experimental, foram $24,9^{\circ} \mathrm{C}$ e $11,2^{\circ} \mathrm{C}$, respectivamente. Os animais foram distribuídos em um delineamento experimental em blocos casualizados dentro de sexo (leves e pesados), com 4 tratamentos, com 8 animais em cada bloco, com duas repetições dentro de cada bloco, sendo cada repetição constituída de um animal. Foi formulada uma dieta referência de acordo com as exigências do NRC (1977) para coelhos em crescimento e, para as demais rações, o feno de mandioca substituiu o farelo de trigo em 10, 20 e $30 \%$. Após a mistura, as rações foram peletizadas a seco, e o fornecimento das mesmas e de água foi à vontade.

As composições percentuais e química das rações encontram-se na tabela 1. Os coelhos foram pesados no início do experimento com 50 dias de idade e no final do experimento com 70 dias de idade. As rações fornecidas e as sobras também foram pesadas. $\mathrm{O}$ abate dos animais, no final do experimento, foi realizado conforme descrição feita por SCAPINELLO (1993). Os níveis de cálcio nos ossos foram determinados por absorção atômica.

O modelo estatístico utilizado para análise das características de desempenho e de carcaça e níveis de cálcio nos ossos foi: $\mathrm{Y}_{j k l m}=\mu+\mathrm{B}_{l}+\mathrm{b}_{1}$ $\left(\mathrm{N}_{j}+\mathrm{N}\right)+\mathrm{b}_{2}\left(\mathrm{~N}_{j}+\mathrm{N}\right)^{2}+\mathrm{S} k+\mathrm{e}_{j k l m}$, em que $\mathrm{Y}_{j k l m}$ foi o valor observado das variáveis estudadas, relativo ao indivíduo $m$, de sexo $k$, de bloco $l$ que recebeu feno de mandioca com nível de inclusão $j ; \mu$ foi a constante geral; $\mathrm{B}_{l}$ foi o efeito do bloco $l$, sendo $l=1$ e 2 ; (1=leve, $2=$ pesados); $b_{l}$ é o coeficiente linear de regressão da variável $\mathrm{Y}$, em função dos níveis de
Tabela 1 - Composição centesimal e química das rações experimentais de acordo com os diferentes níveis de feno de rama da mandioca.

\begin{tabular}{|c|c|c|c|c|}
\hline \multirow[b]{2}{*}{ Ingredientes } & \multicolumn{4}{|c|}{ Rações } \\
\hline & 0 & 10 & 20 & 30 \\
\hline Milho & 30,28 & 30,28 & 30,28 & 30,28 \\
\hline Farelo de soja & 18,10 & 18,10 & 18,10 & 18,10 \\
\hline Farelo de trigo & 30,00 & 20,00 & 10,00 & - \\
\hline Feno de mandioca & - & 10,00 & 20,00 & 30,00 \\
\hline Sabugo de milho & 20,00 & 20,00 & 20,00 & 20,00 \\
\hline Sal comum & 0,40 & 0,40 & 0,40 & 0,40 \\
\hline Premix vitamínico $^{1}$ & 0,18 & 0,18 & 0,18 & 0,18 \\
\hline Premix mineral $^{2}$ & 0,06 & 0,06 & 0,06 & 0,06 \\
\hline Farinha de ossos & 0,93 & 0,93 & 0,93 & 0,93 \\
\hline Bacitracina de zinco & 0,05 & 0,05 & 0,05 & 0,05 \\
\hline \multicolumn{5}{|l|}{ Composição analisada $^{3}$} \\
\hline Matéria seca $(\%)$ & 85,35 & 85,71 & 86,12 & 86,95 \\
\hline Proteína bruta $(\%)$ & 19,30 & 19,18 & 19,04 & 18,81 \\
\hline Energia bruta $(\mathrm{Kcal} / \mathrm{kg})$ & 4.558 & 4.538 & 4.519 & 4.512 \\
\hline Fibra bruta $(\%)$ & 12,86 & 14,67 & 16,47 & 18,20 \\
\hline Cálcio $(\%)$ & 0,50 & 0,70 & 0,91 & 1,08 \\
\hline Fósforo (\%) & 0,44 & 0,40 & 0,35 & 0,30 \\
\hline Taninos $(\mathrm{mg} / 100 \mathrm{~g})$ & 507,15 & 627,90 & 676,20 & 821,10 \\
\hline
\end{tabular}

1- Composição por $1,5 \mathrm{~kg}$ do produto: Vit A, 10.000.000 UI; Vit D, 1.000.000 UI; Vit E, 5.000 mg; Vit K3, 2.000mg; Vit B1,1.600mg; Vit B2, 3.300mg; Vit B6, 1.500mg; Vit B12, 25mg; Pantotenato de cálcio, $16.000 \mathrm{mg}$; Niacina, $22.000 \mathrm{mg}$; Bacitracina de zinco, $30.000 \mathrm{mg}$;

Antioxidante, $20.000 \mathrm{mg}$; Veiculo q.s.p $1.500 \mathrm{~g}$

2- Composição por 0,500 kg do produto: Ferro, 70.000mg; Cobre, $7.000 \mathrm{mg}$; Cobalto, $700 \mathrm{mg}$;

Manganês, 25.000mg; Zinco, 50.000mg; Iodo, 1.000mg; Selênio, 100mg; Veiculo qsp 500g

3- Analise realizada no Laboratório de Nutrição Animal do Departamento de Zootecnia da Universidade Federal de Lavras.

inclusão do feno $j ; b_{2}$ é o coeficiente quadrático de regressão da variável $\mathrm{Y}$, em função dos níveis de inclusão do feno $j ; \mathrm{N}_{j}$ foi o efeito do nível $j$ de inclusão do feno de mandioca para todo $j$ maior que $1 ; \mathrm{N}$ e a média dos níveis de inclusão do feno de mandioca; $\mathrm{S}_{k}$ foi o efeito do sexo $k$, onde $k=1$ e 2 (1 macho, 2 fêmeas) e $\mathrm{e}_{j k l m}$, foi o erro aleatório associado a cada observação.

\section{RESULTADOS E DISCUSSÃO}

As médias de peso vivo aos 70 dias são mostradas na figura 1; e as médias do peso vivo aos 70 dias, ganho de peso diário, consumo diário de ração e conversão alimentar, no período de 50 a 70 dias de idade, de acordo com os níveis de inclusão do feno da rama de mandioca em substituição ao farelo de trigo, são mostradas tabela 2 .

A análise de regressão mostrou efeito linear $(\mathrm{P}<0,05)$ no peso vivo ao abate com a inclusão 


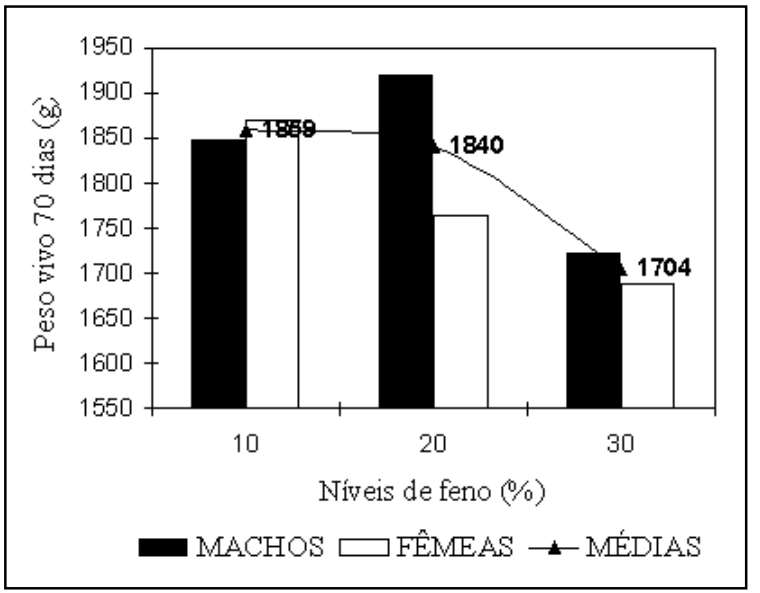

Figura 1 - Peso vivo aos 70 dias de idade de acordo com os diferentes níveis de feno de rama da mandioca.

de diferentes níveis de feno de mandioca. As demais características de desempenho não foram afetadas de forma significativa. O efeito linear, observado no peso ao abate dos animais que receberam ração contendo feno de mandioca, pode estar associado aos efeitos da fibra bruta com a inclusão do feno. Prejuízos semelhantes em função dos elevados níveis de fibra foram observados também por BESEDINA (1970) e CARREGAL (1976, 1983). Outro fator que, possivelmente, pode ter determinado o efeito linear no peso ao abate dos animais é a presença de taninos na rama da mandioca. REED et al. (1982) e FERREIRA (1994) comentam que taninos complexados à proteína e à fibra detergente neutro formam compostos indisponíveis para os animais e, de acordo REED et al. (1982), os taninos podem ligar-se às enzimas do trato digestivo, diminuindo assim a atividade das mesmas e prejudicando o desempenho.

O consumo diário de ração não diferiu entre os tratamentos. DE BLAS et al. (1981) observaram aumento significativo no consumo de matéria seca pelos coelhos com incremento dos níveis de fibra bruta nas rações de 7 a $15 \%$. A conversão alimentar apresentou resultados semelhantes proporcionados pelas rações contendo feno até 20\%; no entanto, houve piora não significativa na conversão alimentar proporcionada pela ração contendo $30 \%$ de feno. Essa baixa eficiência, embora não significativa, deveu-se exclusivamente ao menor ganho de peso, uma vez que o consumo de ração foi semelhante ao dos animais que receberam ração sem feno. A eficiência de utilização da ração foi prejudicada pelo alto teor de fibra. Resultados semelhantes foram observados nos experimentos realizados por HECKMANN \& MEHNER (1971) e CARREGAL $(1976,1983)$, nos quais foram demonstrado o efeito
Tabela 2 - Peso vivo aos 70 dias, ganho médio de peso, consumo médio de ração e a conversão alimentar de coelhos no período de 50-70 dias de idade de acordo com os diferentes níveis de feno de rama da mandioca.

\begin{tabular}{|c|c|c|c|c|c|}
\hline \multirow[b]{2}{*}{ SEXO } & \multicolumn{5}{|c|}{ Níveis de feno } \\
\hline & 0 & 10 & 20 & 30 & Médias \\
\hline & \multicolumn{5}{|c|}{ Peso vivo 70 dias } \\
\hline Machos & 1906 & 1848 & 1918 & 1721 & $1848 \mathrm{a}$ \\
\hline Fêmeas & 1798 & 1870 & 1763 & 1688 & $1779 \mathrm{a}$ \\
\hline \multirow[t]{2}{*}{ Médias ${ }^{1}$} & 1852 & 1859 & 1840 & 1704 & 1813 \\
\hline & \multicolumn{5}{|c|}{ Ganho de peso diário (g) } \\
\hline Machos & 35 & 33 & 36 & 33 & $34 \mathrm{a}$ \\
\hline Fêmeas & 34 & 39 & 35 & 29 & $34 \mathrm{a}$ \\
\hline \multirow[t]{2}{*}{ Médias } & 34 & 36 & 35 & 31 & 34 \\
\hline & \multicolumn{5}{|c|}{ Consumo diário de ração (g) } \\
\hline Machos & 114 & 125 & 121 & 119 & $120 \mathrm{a}$ \\
\hline Fêmeas & 111 & 122 & 117 & 110 & $115 \mathrm{a}$ \\
\hline \multirow[t]{2}{*}{ Médias } & 112 & 123 & 124 & 114 & 122 \\
\hline & \multicolumn{5}{|c|}{ Conversão alimentar } \\
\hline Machos & 3,26 & 3,78 & 3,36 & 3,60 & $3,50 \mathrm{a}$ \\
\hline Fêmeas & 3,26 & 3,13 & 3,34 & 3,79 & $3,38 \mathrm{a}$ \\
\hline Médias & 3,26 & 3,45 & 3,35 & 3,69 & 3,44 \\
\hline
\end{tabular}

1- Efeito linear com inclusão de feno ( $\mathrm{Y}=1927,888$ 4,630000X) $\mathrm{R}^{2}=0,70$

- Médias com de letras minúsculas iguais no sentido de coluna, não difere $(\mathrm{P}>0,05)$ pelo teste $\mathrm{F}$.

negativo da fibra na eficiência de utilização da ração. Nesse caso, também se pode levantar suspeitas do efeito negativo dos taninos presentes na rama da mandioca conforme descrito por REED et al. (1982), embora tal fato exige mais estudos.

$\mathrm{O}$ peso de carcaça e os rendimentos médios de carcaça dos coelhos, de acordo com os níveis de feno encontram-se na tabela 3. Verificou-se um menor peso de carcaça, embora não significativo, em animais que receberam ração contendo $30 \%$ de feno; contudo a análise de regressão não demonstrou efeito $(\mathrm{P}>0,05)$ no rendimento de carcaça com a inclusão do feno da mandioca. Resultados semelhantes foram encontrados por MOUCHREK $\boldsymbol{e t}$ al. (1981), com a obtenção de $61,7 \%$ de rendimento de carcaça com cabeça em coelhos abatidos com 80 dias de idade e por CARREGAL (1983), abatendo coelhos com 70 dias de idade. Provavelmente, os resultados encontrados neste experimento possam ser explicados pela constância do nível protéico nas rações experimentais. CARREGAL (1983) constatou rendimentos de carcaça menores em coelhos alimentados com $14 \%$ de proteína bruta do que em coelhos alimentados com rações contendo 16 e $18 \%$ 
Tabela 3 - Peso de carcaça e rendimento médios de carcaça de coelhos de acordo com os diferentes níveis de feno de rama da mandioca.

\begin{tabular}{lccccc}
\hline & \multicolumn{5}{c}{ Níveis de feno } \\
\cline { 2 - 5 } Sexo & 0 & 10 & 20 & 30 & Média \\
\hline \multirow{5}{*}{ Meso de Carcaça (g) } \\
Fêmeas & 1109 & 1145 & 1096 & 1054 & $1101 \mathrm{a}$ \\
Médias & 1149 & 1142 & 1133 & 1056 & 11,19 \\
& & 1138 & 1170 & 1057 & $1138 \mathrm{a}$ \\
Machos & 62,26 & 61,58 & 61,04 & 61,31 & $61,55 \mathrm{a}$ \\
Fêmeas & 61,64 & 61,53 & 62,16 & 62,40 & $61,89 \mathrm{a}$ \\
Médias & 61,95 & 61,47 & 61,60 & 61,85 & 61,72 \\
\hline
\end{tabular}

Médias com letras minúsculas iguais no sentido da coluna, não diferem $(\mathrm{p}>0,05)$ pelo teste $\mathrm{F}$.

de proteína bruta. Os percentuais médios de cálcio nos ossos (fêmur) de coelhos, de acordo com os níveis de inclusão de feno encontram-se na tabela 4.

Constatou-se que a incorporação de feno às rações experimentais implicou um aumento gradativo do teor de cálcio das mesmas, contudo, a análise de regressão não demonstrou efeito $(\mathrm{P}>0,05)$ nos animais que receberam ração com níveis crescentes de feno. Segundo BESANÇON \& LEBAS (1969) e CHEEKE \& AMBERG (1973), a excreção de cálcio pela urina em coelhos está relacionada com os níveis desse mineral no sangue, e a baixa reabsorção do cálcio ao nível renal levando, conseqüentemente, a uma alta excreção desse cálcio pela urina em coelhos. Esses fatos explicam os níveis de cálcio não alterados nos ossos de coelhos alimentados com as diferentes rações experimentais, e demonstram que estes animais suportam níveis elevados de cálcio nas rações. A análise mostra, no entanto, diferença $(\mathrm{P}<0,05)$ na percentagem de cálcio dos ossos entre sexos. As fêmeas apresentaram uma maior percentagem de cálcio nos ossos em relação aos machos.

Tabela 4 - Percentuais médios de cálcio nos ossos (femur) de acordo com os diferentes níveis de feno de rama da mandioca.

\begin{tabular}{lccccc}
\hline & \multicolumn{5}{c}{ Níveis de feno } \\
\cline { 2 - 6 } Sexo & 0 & 10 & 20 & 30 & Médias \\
\hline \multirow{5}{*}{ Cálcio nos ossos $(\%)$} \\
Machos & 20,35 & 21,02 & 20,89 & 19,47 & $20,43 \mathrm{a}$ \\
Fêmeas & 22,42 & 21,35 & 21,41 & 22,06 & $21,81 \mathrm{~b}$ \\
Médias & 21,39 & 21,18 & 21,15 & 20,76 & 21,12 \\
\hline
\end{tabular}

Médias seguidas por letras diferentes no sentido da coluna diferem $(\mathrm{P}<0,05)$ pelo teste $\mathrm{F}$.
Provavelmente, a ocorrência se deva a maior deposição de cálcio pelas fêmeas à medida que se aproximam da idade de reprodução.

\section{CONCLUSÕES}

Considerando as condições em que o experimento foi realizado, pode-se concluir que o feno da rama da mandioca é viável até $20 \%$ nas rações de coelhos em crescimento, não afetando as características de desempenho e de carcaça.

\section{REFERÊNCIAS BIBLIOGRÁFICAS}

BARBOSA, C. Aproveitamento da parte aérea da mandioca na alimentação animal. Piracicaba, SP, $1972.71 \mathrm{p}$. Dissertação (Mestrado em Ciência Animal e Pastagens) ESALQ, 1972.

BESANÇON, P., LEBAS, F. Utilization digestive réelle et retention du calcium par le lapin en croissance recevant un régime reché en calciun et en phosphore. Annales de Zootechinie, v.18, n.14, p.437-443, 1969.

BESEDINA, G.G. Effect of fibre on digestibility of nutrients by rabbits. Nutrition Abstracts and Reviews, v.40, n.2, p.653, 1970. Abstract.

CARREGAL, R.D. Efeito da idade e de diferentes níveis de fibra bruta sobre a digestibilidade de nutrientes da rações para coelhos em crescimento. Piracicaba, SP, 1976. 70p. Dissertação (Mestrado em Ciência Animal e Pastagens) ESALQ, 1976.

CARREGAL, R.D. Efeito de raças, de diferentes níveis de proteína e fibra bruta, sobre a digestibilidade de nutrientes em rações para coelhos em crescimento. Jaboticabal, SP, 1983. 117p. Tese (Livre Docência) UNESP, 1983.

CHEEKE, P.R., AMBERG, J.W. Comparative calcium excretion by rats and rabbits. Journal of Animal Science, v.37, n.2, p.450-454, 1973.

CORRÊA, H. Produção e composição química de raizes e ramas de mandioca em diversas épocas de colheita e efeitos da poda na produção de raizes. Viçosa, MG, 1972. 49p. Dissertação (Mestrado em Fitotecnia) - Programa de Pós-graduação em Fitotecnia, Universidade Federal de Viçosa, 1972.

DE BLAS, J.C., PEREZ, E., FRAGA, M.J., et al. Effect of diet on feed intake and growth of rabbits from weaning to slaughter at different ages and weights. Journal of Animal Science, v.56 n.6, p.1225-1232, 1981.

FERREIRA, W. M. Os componentes da parede celular vegetal na nutrição de não ruminantes. In: SIMPÓSIO INTERNACIONAL DE PRODUÇÃO DE NÃO RUMINANTES, SOCIEDADE BRASILEIRA DE ZOOTECNIA, REUNIÃO ANUAL, 31, 1994, Maringá. Anais... Maringá : SBZ, 1994. 128p. p.85-113.

FERREIRA, W.M., SARTORI, A.L., SANTIAGO, G. S., et al. Digestibilidade aparente dos fenos de rami (Boehmeria nivea, G.), guandu (Cajanus cajan, L.), soja perene (Glycine wightii, V.) e da palha de feijão (Phaseolus vulgaris, L) em coelhos na fase de crescimento. Arquivo Brasileiro de Medicina Veterinária e Zootecnia, v.49, n.4, p.465-472, 1997. 
GROXKO., M. Mandioca. Acompanhamento da situação agropecuária no Paraná, v.23, n.9, p.89-95, 1997.

HARRIS, D.J., CHEEKE,P.R., TELEK, L. et al. Utilization of alfafa meal and tropical forage by weanling rabbits. Journal Applied Rabbi Research, v.4, p.4-9, 1981.

HECKMANN., F.W., MEHNER, A. Protein and crude fibre contents of mixed feeds for fatening young rabbits. Nutrition Abstracts and Reviews, v.41, n.1, 1971. Aberdeen, Abstract. p. 299.

MENEZES FILHO, J.A.B. Experimentos em coelhos com a fava de Parkia platycephala. Pesquisa Veterinária Brasileira, v.4, p.23-27, 1984.

MOUCHREK., E., VIANA, L.S., GONTIJO, V.P. Índices básicos para melhoramento da alimentação e manejo de coelhos mestiços. Informe Agropecuário, v.7, n.75, p.14-16, 1981.

NASCIMENTO, M.C.L., TAFURY, M.L., MELLO, H.V. et al. Fenos de aveia (Avena strigora, S.) e de rami (Bohemeria nivea, G.) para coelhos em crescimento. In: SOCIEDADE BRASILEIRA DE ZOOTECNIA, REUNIÃO ANUAL 27, 1990, Campinas. Anais... Campinas : SBZ, 1990. p.208.
NATIONAL RESEARCH COUNCIL. (NRC) Nutrients requeriment of rabbits. Washington : National Academy of Science, 1977. 30p.

RAHARJO, Y.C., CHEEKE, P.R., PATTON, N.M., $\boldsymbol{e}$ t $\boldsymbol{a}$. Evaluation of tropical forages and by products feeds for rabbit production. Nutrient digestibility and effect of heat treatment. Journal of Applied Rabbit Research, v.9, p.56-66, 1986.

REED, J.D., MCDOWELL, R.E., VAN SOEST, P.J., et al. Condensed tannins: A factor limiting the use of cassava forage. Journal od the Science of Food and Agriculture, v.33, n.3, p.213-220, 1982.

SCAPINELLO,C. Níveis de proteína bruta e de energia digestível e exigências de lisina e de metionina + cistina, para coelhos da raça Nova Zelândia Branco, em crescimento. Viçosa, MG, 1993. 215p. Tese (Doutorado em Produção Animal) - Universidade Federal de Viçosa, 1993.

ZINSLY, C.F., FERREIRA, W. M. CARREGAL, R.D. Nutrição e alimentação. In: ENCONTRO NACIONAL DE CUNICUlTURA, I, 1985, Belo Horizonte. Anais... Belo Horizonte : UFMG, 1985. 9p.

Ciência Rural, v. 30, n. 3, 2000. 